Jurnal Ilmu Dan Teknologi Kesehatan

Vol 6, No 2, Maret 2019,

ISSN: 2338-9095 (Print)

ISSN: 2338-9109 (online)

\title{
Selektif Vastus Medial Obliquus Exercise Menurunkan Derajat Nyeri Dan Pencapaian Range Of Motion Pasien Dengan Patellofemoral Pain Syndrome
}

\author{
I Wayan Ari Antana, Putu Wira Kusuma Putra, Ida Ayu Ageng Laksmi \\ STIKES Bina Usada Bali \\ Email: putuwirakusumaputra@gmail.com
}

\author{
Artikel history \\ Dikirim, Des $30^{\text {th }}, 2018$ \\ Ditinjau, Jan $15^{\text {th }}, 2019$ \\ Diterima, Feb $20^{\text {th }}, 2019$
}

\section{ABSTRACT}

Patellofemoral Pain Syndrome (PFPS) is pain in the front knee joint due to muscle imbalance especially weakness of the vastus medialis oblique muscle and the stiffness of the hamstrings leads to a patellar position shift to the lateral side (maltracking). Selective VMO exercise is one of conservative therapy to restore VMO muscle strength. The purpose of this study was to determine the effect of Selective Vastus Medial Obliquus Exercise on decreasing the degree of pain and attainment of Range Of Motion patients with PateloFemoral Pain Syndrome. The method of this research used pre experimental design with one group pre-post test design without group control. The number of samples is 13 respondents PFPS who meet the criteria of inclusion and exclusion with purposive sampling. Data were obtained from observation of difference of Visual Analogue Scale (VAS) and ROM (universal goniometer) pain score before (pre-test) and after (post-test) doing exercise therapy. All data were analyzed statistic using Wilcoxon Signed Ranks Test with significance value $(p<0,05)$.. The result of this research shows that there is selective effect of Vastus Medial Obliquus Exercise on the decrease of pain degree with $p$ value $=0.001(\alpha=0,05)$ and attainment of Range Of Motion patient with flexy value $p$ value $=0,039(\alpha=0,05) p$ value $=0.001(\alpha=0.05)$. Decreasing the degree of pain post selective VMO exercise and attainment full ROM showed strengthening of VMO muscle so patella returned to optimal tracking. Suggestion: Measurement of VMO and VL muscle strength can be done with EMG

Keywords: Patellofemoral pain syndrome, Selective VMO exercise, Pain, ROM

\begin{abstract}
ABSTRAK
Patellofemoral Pain Syndrome (PFPS) adalah nyeri pada sendi lutut bagian depan akibat muscle imbalance terutama kelemahan otot vastus medialis oblique dan kekakuan dari hamstrings meyebabkan pergeseran posisi patella ke sisi lateral (maltracking). Selektif VMO exercise merupakan salah satu terapi konservatif untuk mengembalikan kekuatan otot VMO. Tujuan penelitian ini adalah untuk mengetahui pengaruh Selektif Vastus Medial Obliquus Exercise terhadap penurunan derajat nyeri dan pencapaian Range Of Motion pasien dengan PateloFemoral Pain Syndrome. Metode pada penelitian ini menggunakan desain penelitian
\end{abstract}


pre experiment dengan rancangan one group pre-post test design tanpa group kontrol. Jumlah sampel adalah 13 responden PFPS yang memenuhi kriteria inklusi dan eksklusi dengan purposive sampling. Data diperoleh dari pengamatan perbedaan score nyeri Visual Analogue Scale (VAS) dan ROM (universal goniometer) sebelum (pre-test) dan sesudah (post-test) melakukan terapi latihan. Seluruh data dianalisis statistic menggunakan uji Wilcoxon Signed Ranks Test dengan nilai kemaknaan $(\mathrm{p}<0,05)$. Hasil penelitian ini menunjukan terdapat pengaruh Selektif Vastus Medial Obliquus Exercise terhadap penurunan derajat nyeri dengan $\mathrm{p}$ value $=0,001(\alpha=0,05)$ dan pencapaian Range Of Motion pasien dengan nilai flexy $\mathrm{p}$ value $=0,039(\alpha=0,05)$ serta nilai extensi $\mathrm{p}$ value $=0,001$ $(\alpha=0,05)$. Derajat nyeri yang menurun post selektif Vmo exercise dan tercapainya full ROM menunjukan menguatnya otot $V M O$ sehingga patella kembali ke optimal tracking. Saran: Pengukuran kekuatan otot $V M O$ dan $V L$ dapat dilakukan dengan $E M G$

Kata kunci : Patellofemoral pain syndrome, Selektif VMO exercise, Nyeri, ROM

\section{PENDAHULUAN}

\section{Patellofemoral Pain Syndrome (PFPS)}

adalah nyeri pada depan lutut yang berasal dari sendi pattelofemoral (Collins et al. 2008). Menurut Baquie (1997), studi yang dilakukan di Australian sport medicine centre dalam 12 bulan mendapatkan PFPS merupakan salah satu kasus cidera lutut yang sering terjadi dan terhitung 25 $\%$ dari seluruh cidera lutut yang ditemukan di sport medicine centre tersebut (Farzin $\mathrm{H}$ et al, 2013). Penderita PFPS adalah pasien muda di bawah usia 50 tahun (Lankhorst et al. 2012) yaitu diderita oleh $15-33 \%$ populasi dewasa aktif dan $21-45 \%$ pada remaja. Insiden PFPS pada wanita lebih besar 2 dibanding dengan pria dengan perbandingan $2: 1$, sedang insiden tertinggi terjadi populasi atlet wanita yaitu 4 : 1 (Dolak et al. 2011).

PFPS ini terjadi oleh karena adanya ketidakstabilan tulang patela terhadap femur yang bergeser ke sisi lateral akibat dari kelemahan otot vastus medialis oblique (VMO), bahkan otot VMO bisa menjadi distrofi sehingga kontrol kerja otot menurun (Jensen,2008). Tanda yang paling khas dari PFPS adalah adanya nyeri ketika seseorang dari duduk ke bangun dan ketika menaiki tangga, dimana secara bertahap gejalanya akan meningkat seiring dengan akitivitas fisik yang tinggi. Tendon dari otot VMO ini menempel pada sisi medial patella yang berfungsi sebagai stabilisator, sehingga ketika terjadi kelemahan otot VMO maka lateral retinaculum dan vastus lateralis menstabilkan posisi patella ke lateral. Malalignment patella menyebabkan gesekan terus-menerus dan berulang bahkan tekanan berlebih patella ke caudal akan menyebabkan periosteum, cartilage, subchondral patella dan trochlear femur rusak sampai ke permukaan tulang dan nyeri. Hal tersebut dibuktikan oleh Petty et 
al (2011) menyebutkan bahwa penyebab dari PFPS itu diakibatkan oleh adanya kelemahan vastus medialis sehingga terjadinya ketidakseimbangan kinerja dari grup otot quadriceps yang menjadikan kontrol motorik fungsional anggota gerak bawah menjadi berubah dan membentuk gerak kompensasi. Intervensi Patellofemoral Pain Syndrome sejauh ini bervariasi dan semakin maju sehubungan dengan perkembangan penelitian para ahli, beberapa yang telah dilakukan adalah latihan penguatan otot quadriceps secara umum maupun penguatan otot vastus medialis oblique secara selektif (Selektif VMO Exercise), penggunaan foot orthoses, gapping patella, stretching pada illiotibial band hingga pemakaian taping (Barton et al 2012 ; Wolf et al, 2013) .

Penguatan otot quadriceps dengan selektif VMO Exercise merupakan perawatan yang banyak digunakan untuk PFPS, satu teori menyatakan bahwa, jika kekuatan yang dihasilkan oleh $V M O$ sangat penting untuk tracking patela yang tepat, maka penguatan paha depan femoris, terutama closed chain exercise, akan membawa $V M O$ sampai ambang batas yang diperlukan untuk optimal tracking (Leena D,2011). Ini juga dibuktikan dengan penelitian Miao et al(2015), yang membuktikan dengan aktivasi $V M O$ dengan latihan double - semisquat dengan atau tanpa hip adduction pada pasien dengan PFPS dapat membuat balancing Vastus Medial dan Vastus Lateral sehingga patella pada optimal tracking. Data pasien orthopedi di RSU Bali Royal menunjukan banyaknya kasus PFPS yang terjadi, dilihat dari data anamnesa dan klinis rekam medis 25 pasien, menunjukan data terjadinya nyeri lutut merupakan nyeri yang lama atau nyeri lutut kronis dan sudah mendapatkan pengobatan dari konservatif sampai pengobatan yang lebih invasif seperti pemberian injeksi hialuronic acid tanpa memperhatikan stabilitas dan flexibilitas otot-otot pembentuk lutut. Oleh karena itu diperlukanlah penanganan konservatif yang tepat dan efektif berupa terapi $V M O$ exercise yang bertujuan mengembalikan kekuatan otot $V M O$ dan melatih flexibilitas serta fungsi propioseptik anggota gerak bawah (Karandika et al,2011 ; Nobre ,2012).

\section{METODE}

Penelitian ini menggunakan desain penelitian pre eksperiment yaitu eksperimen yang dilakukan dengan tidak mempunyai batasan-batasan yang ketat terhadap randomisasi pada saat yang sama dapat mengontrol ancaman-ancaman validitas. Adapun dengan rancangan one 
group pre-post test design tanpa group kontrol yaitu eksperimen yang dilakukan dengan pre-test sebelum dilakukan perlakuan dan post-test setelah diberikan perlakuan (Notoatmodjo, 2010).

Populasi dalam penelitian ini adalah pasien yang terdiagnosa PFPS yang berobat di poliklinik Orthopedi Rumah Sakit Bali Royal Hospital. Data dari rekam medis RSU Bali Royal pada bulan JuliSeptember 2017 terdapat 74 pasien yang terdiagnosa PFPS, sedangkan jumlah ratarata perbulan pasien yang terdiagnosa PFPS sekitar 25 pasien. Teknik sampel yang digunakan adalah purposive sampling dengan kriteria Inklusi : Pasien yang terdiagnosa PFPS yang berobat yang bersedia menjadi responden, fase kronis dan berumur dewasa ( $\geq 14$ tahun) sedangkan Kriteria ekslusi : Pasien yang terdiagnosa PFPS yang berobat dipoliklinik Orthopedi Rumah Sakit Bali Royal Hospital yang masih ada luka post Total Knee Replacement, tidak melakukan rutin 2 kali terapi latihan di rumah dan meminum obat anti nyeri. Penelitian dilakukan di poliklinik Orthopedi Rumah Sakit Bali Royal Hospital pada bulan Februari sampai Juni 2018. Instrumen penelitian berupa lembar observasi berisi identitas responden seperti nama, umur, jenis kelamin, score nyeri dan ROM sebelum dan sesudah perlakuan. Score nyeri diukur dengan metode $V A S$ sedangkan ROM diukur dengan menggunakan goniometer. Penelitian dilakukan pada kelompok pasien dengan PFPS yang melakukan terapi selektif $V M O$ exercise dengan melihat perbedaan score nyeri dan $R O M$ sebelum (pre-test) dan sesudah (post-test) melakukan terapi latihan. Pengukuran dilakukan sebanyak dua kali yaitu pada pertemuan pertama dan 2 minggu setelah melakukan terapi latihan rutin di rumah.

Analisis bivariate menguraikan mean (rata-rata) skala nyeri dan $R O M$ sebelum dan sesudah perlakuan selama dua kali perlakuan yaitu pada pertemuan pertama dan 2 minggu setelah terapi latihan dilakukan di rumah dengan durasi 25 repetisi 3 set. Uji normalitas dilakukan terlebih dahulu yaitu dengan uji Shapiro wilk. Apabila data berdistribusi normal, uji analisis yang digunakan paired sampel $t$ test, sedangkan apabila data tidak berdistribusi normal, uji analisis yang digunakan yaitu Wilcoxon Signed Ranks Test untuk menilai score nyeri dan ROM sebelum dan sesudah perlakuan dengan nilai derajat kemaknaan $\mathrm{p} \leq 0,05$ dengan taraf kepercayaan 95\%. Ho ditolak apabila $\mathrm{p} \leq 0,05$ (Hidayat, 2011)

\section{HASIL DAN PEMBAHASAN}

Berdasarkan Tabel 5.2 dapat diketahui dari 13 responden yang berpartisipasi dalam 
penelitian ini, didapat mayoritas rentang

$(61,5 \%)$

umur 26-35 tahun sebanyak 8 orang

Distribusi Frekuensi Responden Berdasarkan Lama Menderita di Poliklinik Orthopodi RSU Bali Royal Tahun 2018

\begin{tabular}{ccc}
\hline $\begin{array}{c}\text { Lama menderita } \\
\text { (bulan) }\end{array}$ & Frekuensi (n) & Persentase (\%) \\
\hline 1 & 4 & 30,8 \\
2 & 2 & 15,4 \\
3 & 1 & 7,7 \\
4 & 2 & 15,4 \\
5 & 2 & 15,4 \\
6 & 1 & 7,7 \\
12 & 1 & 7,7 \\
\hline Total & $\mathbf{1 3}$ & $\mathbf{1 0 0}$ \\
\hline
\end{tabular}

Berdasarkan Tabel 1 dapat diketahui dari

13 responden yang berpartisipasi dalam penelitian ini, didapat mayoritas lama menderita selama 1 bulan sebanyak 4 orang $(30,8 \%)$.
Analisis pengaruh Selektif Vastus Medial

Obliquus Exercise terhadap penurunan derajat nyeri dan pencapaian Range $O f$ Motion

Tabel 2 Pengaruh Selektif Vastus Medial Obliquus Exerciseterhadap Penurunan Derajat Nyeri Dan Pencapaian Range Of Motion

\begin{tabular}{ccc}
\hline Variabel & $\mathbf{Z}$ & P value \\
\hline Derajat Nyeri & $-3,269$ & 0,001 \\
Flexi & $-2,060$ & 0,039 \\
Extensi & $-3,419$ & 0,001 \\
\hline
\end{tabular}

Berdasarkan hasil penelitian, dari 13 responden didapatkan terjadi penurunan derajat nyeri dimana derajat nyeri sebelum VMO exercise (pre test) 4.15 dan derajat nyeri sesudah VMO exercise 1.38. Hasil uji Wilcoxon Signed Rank Test didapatkan $\mathrm{p}$ value sebesar $0,001(\alpha=0,05)$ yang artinya bahwa $\mathrm{p}$ value $<0,05$, sehingga hipotesis dalam penelitian ini diterima, dimana secara statistik ada pengaruh selektif $V M O$ exercise terhadap penurunan derajat nyeri.

Pada nilai flexy terjadi membesarnya sudut flexy dimana sudut flexy sebelum VMO exercise (pre test) 131.92 dan besarnya 
sudut flexy sesudah VMO exercise 135 (full flexy). Hasil uji Wilcoxon Signed Rank Test didapatkan bahwa $\mathrm{p}$ value $=$ $0,039(\alpha=0,05)$ yang artinya bahwa $p$ value $<0,05$, sehingga hipotesis dalam penelitian ini diterima, dimana secara statistik ada pengaruh selektif vastus medial obliquus exercise terhadap pencapaian nilai flexy. Pada nilai extensi terjadi penurunan sudut extensi dimana sebelum terapi selektif $V M O$ exercise (pretest) sebesar 5.76 dan setelah selektif vmo exercise menjadi $0^{\circ}$ (full extensi) . Hasil uji Wilcoxon Signed Rank Test didapatkan bahwa $\mathrm{p}$ value $=0,001$ $(\alpha=0,05)$ yang artinya bahwa $p$ value $<$ 0,05 , sehingga hipotesis dalam penelitian ini diterima, dimana secara statistik ada pengaruh selektif vastus medial obliquus exercise pada pencapaian nilai ektensi.

Mengembalikan fungsi dan kekuatan otot quadriceps terutama otot $V M O$ adalah hal utama dalam proses rehabilitasi dari PFPS. Sehingga pemilihan exercise yang sesuai dengan biomekanik sendi patelofemoral akan memaksimalkan dari patella. Menurut Harvei et al (2011), dalam sistematik review yang menganalisa 10 studi penelitian, semua penelitian ini menunjukkan efek positif terapi exercise otot quadricep terhadap penurunan rasa nyeri dan peningkatan ROM. Selektif VMO exercise selain menguatkan otot VMO, akan mengembalikan fleksibilitas dari otot pendukung lutut seperti hamstring, ITB, gastrosoleus, quadrisep yang mengembalikan flexi dan ekstensi menjadi penuh (Waryasz \& McDemrmott, 2008; Collado, 2010). Penelitian yang dilakukan oleh Leena D (2011) yang mebandingkan General Quadriceps strengthening dengan selective Vastus medialis Obliquus strengthening pada pada masing - masing 10 responden dengan Patellofemoral Pain Syndrome membuktikan bahwa kedua jenis latihan tersebut dapat menurunkan derajat nyeri dan meningkatkan Range of Motion akan tetapi selektif VMO Strengthening lebih efektif dibandingkan general quadriceps strengthening dimana 10 responden yang melakukan selektif VMO Exercise menghasilkan Knee Functional Score yang lebih baik. Penelitian yang dilakukan oleh Jamie et al (2012) pada sistematik reviewnya juga menyatakan exercise penguatan otot quadriceps sangat efektif untuk menurunkan nyeri dan meningkatkan fungsional lutut. Penelitian Miao et al (2015) juga menunjukan efektivitas dari aktivasi otot $V M O$ pada latihan semisquat dengan hip abduksi ataupun tanpa hip aduksi dalam menyeimbangkan $V M O$ dan $V L$.

Berdasarkan hasil penelitian dan uraian diatas, peneliti mendapatkan program latihan Selektif VMO Exercise yang 
dilakukan 2 minggu oleh pasien dengan PFPS sangat memberikan perngaruh besar terhadap fungsi lutut responden dengan berkurangnya nyeri tanpa menggunakan obat anti nyeri dan meningkatnya $R O M$ secara signifikan. Peneliti mengamati pada saat apprehension test dan mobility test 2 minggu post test pada masing-masing responden, menunjukan skala nyeri antara 1 dan skala 2 (VAS) dimana responden menyatakan dapat naik turun tangga lebih baik, dari posisi duduk ke berdiri sudah lebih nyaman, responden pun dapat berjalan lebih jauh dengan nyaman pada responden usia tua dan pada responden muda dapat berlari dengan lebih nyaman. Peneliti melihat belum terjadi perubahan signifikan dari massa otot VMO, akan tetapi sudah memberikan kekuatan untuk menarik patella kearah medial ini ditunjukan dengan berkurangya nyeri dari responden. Latihan straight leg raise memberikan beban pada otot quadriceps sehingga massa otot dan kekuatan otot meningkat, akan tetapi pada selektif $V M O$ exercise ini posisi kaki diarahkan ke lateral sehingga titik beban fokus pada otot $V M O$, gerakan ini yang melatih otot $V M O$ menjadi lebih kuat untuk menarik patella kearah medial. Gerakan Ball squees juga meberikan pembebanan pada otot $V M O$ sehingga otot $V M O$ menjadi lebih kuat. Gerakan latihan Quad set memberikan pembebanan pada quadriceps akan tetapi lebih melatih untuk menghilangkan kekakuan dari hamstring sehingga responden dapat mencapai full extensi sehingga patella tilt ke lateral pun tidak terjadi. Gerakan heel slide membantu responden untuk mencapai full flexy dan gait dari responden pun sudah benar ketika dievaluasi. Peneliti dapat menyimpulkan bahwa latihan penguatan otot $V M O$ merupakan penanganan konservatif yang paling efektif pada kasus PFPS , dimana kembalinya kekuatan otot $V M O$ merupakan kembalinya fungsi stabilisasi dari otot pendukung lutut dan mengembalikan fleksibilitas dari otot pendukung lutut seperti hamstring , ITB, gastrosoleus, quadrisep yang membantu flexi dan ekstensi dari lutut mencapai full motion sehingga kembalinya kerja patella pada optimal tracking yang menghindari gesekan patella dengan trochlear femur sehingga tidak terjadi nyeri. Peneliti juga dapat menyimpulkan bahwa "exercise is medicine".

\section{SIMPULAN}

Ada pengaruh selektif VMO Execise terhadap penurunan derajat nyeri pencapaian $R O M$ pasien dengan PFPS di Poliklinik RSU Bali Royal dengan p value 
nyeri $0.001(<0.05), \quad \mathrm{p}$ value flexy $0.039(<0.05)$ dan $p$ value extensi 0.001 $(<0.05)$. Penelitian selanjutnya tentang PFPS menggunakan variabel lain yang dapat mempengaruhi tingkat nyeri dan $R O M$ seperti tipe jenis latihan yang lain, evaluasi kekuatan otot dengan alat $E M G$, evaluasi dengan skyline view, penggunaan taping, patella brace atau penggunaan alat bantu strengthening berupa theraband atau yang lainnya

\section{DAFTAR RUJUKAN}

Barton, CJ, Bonanno D, Levinger P, Menz HB. 2012. Foot and ankle characteristics in patellofemoral pain syndrome: a case control and reliability study.Amerika. J Orthop Sports Phys Ther 2010;40:286-96

Collin, Prins MR, van der Wurff P. 2008. Females with patellofemoral pain syndrome have weak hip muscles: a systematic review. Norwaygia. Aust $J$ Physiother 2009;55:9-15

Dolak, K.L., Silkman, C., McKeon, J.M., Hosey, R.G., Latterman, C., Uhi, T.L., 2011. Hip strengthening prior to functional exercises reduces pain sooner than quadriceps strengthening in females with patellofemoral pain syndrome: a randomized clinical trial. J. Orthop. Sports Phys. Ther. 41, 560-57

Farzin, H. Reza M., Tohid S.B. 2013. Patellofemoral Pain Syndrome and Modifiable Intrinsic Risk Factors;How to Assess and Address.Iran. Asian Journal of Sports Medicine. Volume 4 (Number 2), June 2013, Pages: $85-10$
Harvie D, O'Leary T, Kumar S. 2011. A systematic review of randomized controlled trials on exercise parameters in the treatment of patellofemoral pain: what works? $J$ Multidiscip Healthc 2011;4:383-92

Hidayat, A.A. 2011. Metode Penelitian Keperawatan dan Teknik Analisa Data, Jakarta: Salemba Medika

Jamie L. Frye, PhD, ATC, Lindsay N. Ramey, BS,Joseph M. Hart, PhD, ATC. 2012. The Effects of Exercise on Decreasing Pain and Increasing Function in Patients With Patellofemoral Pain Syndrome: A Systematic Review.Sport Health. vol 4. No 3 DOI: $10.1177 / 1941738112441915$

Jensen, R. 2008. "Patellofemoral pain syndrome: studies on a treatment modality, somatosensory function, pain, and psychological parameters" (tesis). Norwaygia. University of Bergen (di unduh 19 September 2012). Available from:http://www.ncbi.nlm.nih.gov/p mc/articles/PMC2795830/

Karandika, N. Ortiz-Vargas, O.O. 2011. Kinetic chain: a revies of the concept and its clinical applications. America. The American Academy of Physical Medicine and Rehabilitation ;3:739-745

Lankhorst, N.E. Zeinstra, Sita M.A.B. Van Middelkoop, M. 2012. Risk factor for patellofemoral pain syndrome: a systematic review. Netherland. British Journal of Sport Medicine. doi:10.2519/jospt.2012.3803.Availa ble from: http://www.jospt.org/mem bers/getfile.asp?i $d=5541$

Leena, D. 201).Effectiveness of General Quadriceps strengthening versus selective Vastus Medialis Obliquus strengthening in Patellofemoral Pain 
Syndrome. India. Indian Journal of Basic \& Applied Medical Research; December 2011: Issue-1, Vol.-1, P. $71-76$

Miao, P.Yi Xu, Cuihuan Pan, Hao Liu , Chuhuai W. 2015. Vastus medialis oblique and vastus lateralis activity during a double-leg semisquat with or without hip adduction in patients with patellofemoral pain syndrome.China. BMC Musculoskeletal Disorders.16:289 DOI 10.1186/s12891-015-0736-6

Nobre, T.L. 2012. Comparison of exercise open kinetic chain dan closed kinetic chain in the rehabilitation of patellofemoral dysfunction: an update revision. Brazil. Clinical Medicine and Diagnosis. 2(3):7-11

Notoatmodjo, S. 2010. Metodelogi Penelitian Kesehatan, Jakarta : Rineka Cipta
Petty, E. Verdonk, P. Steyaert, A. Bossche, L.V. Van den Boecke, W. Thijs, Y. Witvouw, E. 2011. Vastus medialis obliquus atrophy: does it exist in patellofemoral pain syndrome?. Belgia. American Journal of Sport Medicine. 39:1450

Waryasz. G.R, McDermott, A.Y. 2008. Patellofemoral pain syndrome (PFPS): a systematic review of anatomy and potentials risk factors. USA. Dynamic Medicine. (di unduh 10 Januari 2013). Available from: http://goo.gl/oE33w

Wolf, P. Andree E, Andreas G K, Raymond B, Ingo Volker R, Gerd-Peter B, Christian L. 2013. Patellofemoral pain syndrome. Germany. Knee Surg Sports Traumatol Arthrosc . 22:2264--62274 